\title{
Determination of the prevalence and pattern of menstrual disorders in college going adolescent girls in rural Haryana
}

\author{
Verma Vaishali*, Das Banashree, Nath Jayati
}

Department of Obstetrics and Gynecology, Gurugram, Haryana, India

Received: 19 April 2021

Revised: 24 May 2021

Accepted: 25 May 2021

\section{*Correspondence:}

Verma Vaishali,

E-mail: Vaishaliverma93@gamil.com

Copyright: ( $)$ the author(s), publisher and licensee Medip Academy. This is an open-access article distributed under the terms of the Creative Commons Attribution Non-Commercial License, which permits unrestricted non-commercial use, distribution, and reproduction in any medium, provided the original work is properly cited.

\begin{abstract}
Background: Adolescence is the transitional period from puberty to adulthood, causing rapid physical, cognitive, social and emotional changes. Any deviation of normal menstrual pattern is one of the reasons of severe stress and academic losses on many. The aim of the study was to determine prevalence and pattern of menstrual disorders in college going adolescent girls.

Methods: A descriptive cross-sectional study was conducted in a medical college of Gurugram district of Haryana, North India. A semi-structured, pretested questionnaire was used to ask about the characteristics of girl's menstruation: age of menarche; regularity/irregularity of menstruation, interval and duration; presence of amenorrhoea; amount of blood loss; degree of pain during menstruation; activity during menstruation and BMI.

Results: All the girls were in the age group 17 to 19 years i.e.; in the late adolescent period with the mean age of $18.2 \pm 0.73$ years. $81.66 \%$ girls attained menarche between 12 to 14 years of age. $3.66 \%$ girls attained early menarche and $0.33 \%$ girls attained menarche late. 19 had scanty menstrual bleeding and 7 suffered from secondary amenorrhea. 27 girls suffered from heavy menstrual bleeding. 78.3\% adolescent girls had various degrees of dysmenorrhea with $8.66 \%$ had severe dysmenorrhea. $17.66 \%$ girls had high BMI and $11 \%$ girls for underweight.

Conclusions: There was a high prevalence of menstrual disorders among adolescent girls which affects their social and academic lives. Thus, more attention should be paid to identify and treat these menstrual morbidities.
\end{abstract}

Keywords: Adolescent girls, Dysmenorrhea, Menstrual irregularities, Body mass index

\section{INTRODUCTION}

Adolescence is the transitional period from puberty to adulthood, causing rapid physical, cognitive, social and emotional changes. Along with these changes' adolescents need to cope with academic and environmental challenges too. Menstruation is a periodic and cyclical shedding of progestational endometrium along with blood loss and many hormonal changes and this process is regulated by hormones in the hypothalamo-pituitary-ovarian axis.

Normally menarche begins by 10-16 years of age. Most of the menstrual cycles are anovulatory in the first 2-3 years following menarche due to the relative immaturity of the hypothalamic pituitary-ovary axis. This causes irregular cycles with varying cycle lengths. There after the capacity for oestrogen positive feedback on the anterior pituitary develops with the subsequent mid-cycle LH surge and ovulation, resulting in regulation of the menstrual cycle. ${ }^{1}$

Normal ovulatory cycles range from 21 to 35 days and normal menstrual cycles are characterized by cycle length of $28 \pm 7$ days, duration of flow of $4 \pm 2$ days and a blood loss of $40 \pm 20 \mathrm{ml}$. The mean volume of menstrual blood loss is $43 \mathrm{ml}$, with a normal range of $20-80 \mathrm{ml}^{2}$ Any deviation of normal menstrual pattern is one of the reasons 
of severe stress and academic losses on many adolescent girls. Menstrual abnormalities can be affected by a number of factors including hormonal factors, family history, bleeding disorders, chronic illness, any neoplasm etc.

The aim of the study was to determine the prevalence and pattern of menstrual disorders in college going adolescent girls.

\section{METHODS}

A college based descriptive cross-sectional study was conducted in the month of July to October 2019 in a medical college of Haryana. With the prevalence of menstrual disorder 76.9 (study by Kulshrestha et al) and absolute error of $5 \%$ with $5 \%$ level of significance and $10 \%$ non-response rate the minimum sample size calculated was 300 , using the formula $4 \mathrm{pq} / \mathrm{l}^{2} .^{3}$ Among 561 girls studying in MBBS, BDS and Nursing students in $1^{\text {st }}$ and $2^{\text {nd }}$ year were targeted. A convenient sampling technique was used to select 300 adolescent girls aged between 17-19 years among the above girls.

A semi-structured, pretested, semi open-ended, interviewer administered, bilingual questionnaire was used to collect information regarding socio-demographic profile like age, sex, education, occupation etc. The participants were also asked about the characteristics of their menstruation: age of menarche; regularity/irregularity of menstruation in interval and duration; presence of amenorrhoea (secondary); amount of blood loss (number of pads used); pain during menstruation and degree of pain; activity during menstruation. Later they were clinically assessed for their weight, height, BMI and any abnormal hair growth.

\section{Inclusion criteria}

Girls who were willing to participate in the study were included in the study.

\section{Exclusion criteria}

Girls who were suffering from any chronic illnesses and those who were not willing to participate were excluded.

\section{Operational definitions for menstrual disorders}

Secondary amenorrhoea: No period during the last 3 months. (a) regular menstruation: cycle repeated about once every 28-32 days with duration 5-7 days; (b) scanty menstrual bleeding: cycle monthly repeated about once every $>32$ days or duration of period $<3$ days and slight blood loss (using <1 pad/day); (c) heavy and prolonged menstrual bleeding: cycle repeated about once every $\leq 21$ days or duration of period $>7$ days and blood loss $>80 \mathrm{ml}$ (using $\geq 4$ pads/day); and (d) dysmenorrhoea: painful menstruation (mild, moderate or severe).
Statistical analysis was done using a licensed version of SPSS 21. Descriptive analysis was done by calculating proportions, means and standard deviation. Chi square/Fishers exact test was applied. The ethical clearance was obtained from Institutional Ethics Committee.

\section{RESULTS}

All the girls were in the age group 17 to 19 years i.e.; in the late adolescent period with the mean age of $18.2 \pm 0.73$ years. Out of these, most of the girls belonged to the middle or upper middle socioeconomic status according to the modified BG Prasad scale (275 girls) and only 14 girls belonged to the lower class. Girls targeted in this study were studying in MBBS, BDS and nursing who belonged to the adolescent age group. Girls were distributed according to the age of onset of menstruation. Most of the girls attained menarche between 12 to 14 years of age i.e.; $81.66 \%$ with maximum at 13 years of age i.e. $37.33 \%$. $3.66 \%$ girls attained early menarche and $0.33 \%$ girls attained menarche late. But most of the girls had normal menstrual cycle i.e.; $76.66 \%$. Rest of the adolescent girls had either scanty ( $<3$ days duration of bleeding) $3.91 \%$ and prolonged menstrual bleeding ( $>7$ days duration of bleeding) $20.33 \%$.

Amount of blood flow measured by the number of pads used per day. Blood loss was mostly normal for 247 girls despite whether their menses regular or not. Out of the 300 , 19 had scanty menstrual bleeding i.e.; they were using 1-2 pads per day which was not completely soaked and 7 suffered from secondary amenorrhea. 27 girls were suffering from heavy menstrual bleeding i.e. they were changing fully soaked pads multiple times per day $(>4$ pads/day). Dysmenorrhoea was the most common menstrual disorder in our study. It was characterized as mild, moderate and severe by WaLIDD scoring system which includes working ability, location, intensity and days of pain. A total of 235 (78.3\%) adolescent girls had various degrees of dysmenorrhea. Severe dysmenorrhea was seen in $8.66 \%$ girls which was affecting their personal and academic life and also an important cause in causing a dent in the school/college attendance.

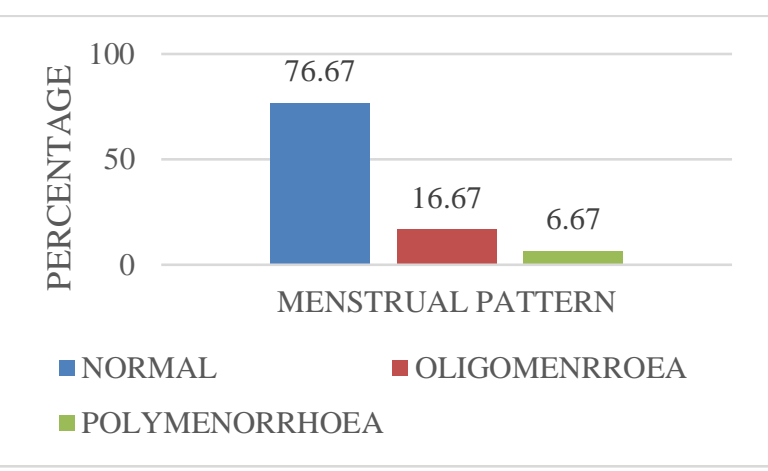

Figure 1: Distribution of study participants according to pattern of menstruation. 
Table 1: Distribution of general characters of study participants $(\mathrm{N}=\mathbf{3 0 0})$.

\begin{tabular}{|c|c|c|}
\hline Characters & Numbers & $\begin{array}{l}\text { Percentage } \\
(\%)\end{array}$ \\
\hline \multicolumn{3}{|l|}{ Age group (years) } \\
\hline 17 & 57 & 19.00 \\
\hline 18 & 126 & 42.00 \\
\hline 19 & 117 & 39.00 \\
\hline \multicolumn{3}{|l|}{ Mean age: $18.2 \pm 0.73$ years } \\
\hline \multicolumn{3}{|l|}{ Socioeconomic status* } \\
\hline Class I (Upper) & 87 & 29.00 \\
\hline Class II (Upper middle) & 114 & 38.00 \\
\hline Class III (Middle) & 64 & 21.30 \\
\hline Class IV (Lower middle) & 21 & 7.00 \\
\hline Class V (Lower) & 14 & 4.70 \\
\hline \multicolumn{3}{|l|}{ Course } \\
\hline MBBS & 144 & 48.00 \\
\hline BDS & 46 & 15.30 \\
\hline Nursing & 110 & 36.60 \\
\hline \multicolumn{3}{|l|}{ Diet } \\
\hline Mixed & 104 & 34.66 \\
\hline Vegetarian & 196 & 65.33 \\
\hline \multicolumn{3}{|l|}{ BMI $\left(\mathrm{kg} / \mathrm{m}^{2}\right)$} \\
\hline Underweight $(<18.5)$ & 33 & 11.00 \\
\hline Normal (18.5-24.9) & 214 & 71.33 \\
\hline Overweight (25-29.9) & 39 & 13.00 \\
\hline Obese $(>30)$ & 12 & 4.67 \\
\hline
\end{tabular}

Menstrual abnormalities not only due to menstrual irregularities or scanty or prolonged menstrual bleeding but also due to abnormal hair growth which was one of the causes of depression and anxiety in college going adolescent girls. In our study 33 such girls were suffering from hirsutism and out of these, 15 girls also suffered from irregular menstrual cycles. Persistent menstrual irregularities can be due to polycystic ovarian syndrome (PCOS) rather than immature hypothalamo-pituitary gonadal axis. Once diagnosed PCOS requires drastic changes in lifestyle for correction. In our study 18 girls were diagnosed cases of PCOS and 11 were not on any treatment $(3.66 \%)$.

Table 2: Distribution of participants according to the menstrual pattern.

\begin{tabular}{|c|c|c|}
\hline Distribution variables & Numbers & $\begin{array}{l}\text { Percentage } \\
(\%)\end{array}$ \\
\hline \multicolumn{3}{|c|}{ Age of menarche- Age (years) } \\
\hline$<10$ & 3 & 1.00 \\
\hline 10 & 8 & 2.66 \\
\hline 11 & 20 & 6.66 \\
\hline 12 & 94 & 31.33 \\
\hline 13 & 112 & 37.33 \\
\hline 14 & 39 & 13.00 \\
\hline 15 & 17 & 5.66 \\
\hline 16 & 6 & 2.00 \\
\hline$>16$ & 1 & 0.33 \\
\hline \multicolumn{3}{|c|}{ Duration of menstrual bleeding (days) } \\
\hline$<3$ & 9 & 3.91 \\
\hline $3-7$ & 230 & 76.66 \\
\hline$>7$ & 61 & 20.33 \\
\hline \multicolumn{3}{|l|}{ Amount of blood loss } \\
\hline Normal blood flow & 247 & 82.33 \\
\hline Heavy menstrual bleeding & 27 & 9.00 \\
\hline Scanty menstrual bleeding & 19 & 6.33 \\
\hline Secondary amenorrhoea & 7 & 2.33 \\
\hline \multicolumn{3}{|l|}{ Degree of pain } \\
\hline No pain & 65 & 21.66 \\
\hline Mild & 164 & 54.66 \\
\hline Moderate & 45 & 15.00 \\
\hline Severe & 26 & 8.66 \\
\hline \multicolumn{3}{|l|}{ Abnormal hair growth } \\
\hline $\begin{array}{l}\text { Adolescent with regular } \\
\text { menses }(\mathrm{N}=247)\end{array}$ & 15 & 6.10 \\
\hline $\begin{array}{l}\text { Adolescent with irregular } \\
\text { menses }(\mathrm{N}=53)\end{array}$ & 18 & 33.96 \\
\hline \multicolumn{3}{|c|}{$\begin{array}{l}\text { Based on treatment who already diagnosed PCOS } \\
(\mathrm{N}=18)\end{array}$} \\
\hline On treatment & 7 & 38.89 \\
\hline Not on treatment & 11 & 61.11 \\
\hline
\end{tabular}

Table 3: Association of menstrual disorder.

\begin{tabular}{|c|c|c|c|}
\hline \multirow[t]{2}{*}{ Parameters } & \multicolumn{2}{|c|}{ Menstrual disorder } & \multirow[t]{2}{*}{ P value } \\
\hline & Present N (\%) & Absent N (\%) & \\
\hline \multicolumn{4}{|l|}{ Socioeconomic status } \\
\hline Upper $(\mathrm{N}=87)$ & $15(17.24)$ & $67(82.66)$ & \multirow[t]{3}{*}{0.001} \\
\hline Middle $(\mathrm{N}=178)$ & $45(25.28)$ & $138(74.72)$ & \\
\hline Lower $(\mathrm{N}=14)$ & $10(71.4)$ & $4(28.6)$ & \\
\hline \multicolumn{4}{|l|}{ Diet } \\
\hline Vegetarian $(\mathrm{N}=196)$ & $36(18.37)$ & $160(81.63)$ & \multirow[t]{2}{*}{0.01} \\
\hline $\operatorname{Mix}(\mathrm{N}=104)$ & $34(32.7)$ & $70(67.3)$ & \\
\hline \multicolumn{4}{|l|}{ BMI $\left(\mathrm{kg} / \mathrm{m}^{2}\right)$} \\
\hline Underweight $(\mathrm{N}=33)$ & $14(42.42)$ & $19(57.58)$ & \multirow[t]{4}{*}{0.001} \\
\hline Normal $(\mathrm{N}=214)$ & $36(16.82)$ & $178(83.18)$ & \\
\hline Overweight $(\mathrm{N}=39)$ & $15(38.46)$ & $24(61.54)$ & \\
\hline Obese $(\mathrm{N}=12)$ & $5(41.67)$ & $7(58.33)$ & \\
\hline
\end{tabular}




\begin{tabular}{|lllc|}
\hline Parameters & $\begin{array}{l}\text { Menstrual disorder } \\
\text { Present N (\%) }\end{array}$ & Absent N (\%) & \\
\hline Course & & & \\
\hline MBBS $(\mathrm{N}=144)$ & $35(24.33)$ & $109(75.67)$ & 0.5 \\
\hline BDS $(\mathrm{N}=46)$ & $8(17.39)$ & $36(82.61)$ & \\
\hline
\end{tabular}

Body mass index (BMI) of the adolescent girls is not only related to the nutritional status but is also frequently correlated with menstrual irregularities. $65.33 \%$ girls were vegetarian and the rest had mixed dietary pattern. Indian vegetarian diet is usually high in carbohydrates and fats which reflects poorly on the nutritional status of the girls. This can be a cause either low or high BMI. Still most of the girls in our study had normal BMI (18.5 to $24.9 \mathrm{~kg} / \mathrm{m}^{2}$ ). 53 girls had high BMI and out of these $38.18 \%$ girls suffered from menstrual irregularities. 178 girls with normal BMI had no menstrual irregularities but irregularities were more common in girls with low or high BMI.

\section{DISCUSSION}

In the present study the age of the menarche ranged from 10 to 16 years with the average age being 13 years. Mean age of menarche varies from population to population. Some studies reported the mean age of menarche 11.8 $2 \pm 1.42$ years in Allahabad, $12.60 \pm 0.99$ in Aligarh City and $14.33 \pm 0.00$ years in Chhattisgarh. ${ }^{3-5}$ In our study the minimum age of menarche was 9 years but, in a study, conducted in Aligarh minimum age of menarche was 11 years. The onset of menarche varies in rural and urban areas because of the variations in the lifestyle. Our study showed that the menstrual problems were varying lengths of the menstrual cycle, scanty or profuse menstrual bleeding and dysmenorrhea of varying degrees.

In our study $16.66 \%$ adolescent girls had decreased/scanty menstrual flow which is an important factor in causing psychological disturbances like anxiety, depression etc. Similar results were reported in studies conducted by Kulshrestha et al and Vanitha et at in the Indian girls. ${ }^{6}$ Heavy menstrual bleeding puts the girls at the risk of anemia and affects the quality of life adversely. We observed heavy menstrual bleeding in $6.67 \%$ of the adolescent girls. Majority of the girls in our study had cycle length of 21 to 35 days that is $706.6 \%$. This is comparable with the study conducted in Nigeria in which 81 point $1 \%$ girls reported cycle length between 21 and 35 days. $^{7}$

Dysmenorrhea is a serious menstrual abnormality that affects the girl's daily activity or academic attendance. $78.32 \%$ girls were suffering from various degrees of menstrual pain which was the most common menstrual abnormality in our study. $8.66 \%$ girls suffered from severe dysmenorrhea causing significant loss of school/college attendance. Studies conducted by Arpana et al in South India showed $53.9 \%$ girls suffered from dysmenorrhea and similar results were found by Chakrabarti et al. ${ }^{8,9}$ Out of those who suffered from dysmenorrhea in our study $8.66 \%$ complained of severe dysmenorrhea, 15 of moderate and $54.66 \%$ of mild dysmenorrhea. In a study conducted by Karout et al in Saudi Arabia the prevalence of dysmenorrhea was $60.3 \%$ while $15 \%$ in a study conducted by Lakshmi et al from India. ${ }^{10,11}$ The difference in various studies may be related to the cultural differences and pain perception and pain threshold of different populations.

BMI plays an important role for menstrual cycle regularity. High BMI increases the risk of ovulatory dysfunction, heavy menstrual blood loss, amenorrhea, painful menstruation. ${ }^{12}$ In our study we observed that most of the adolescent girls had normal BMI $\left(18.5-24.9 \mathrm{~kg} / \mathrm{m}^{2}\right)$ i.e.; $71.33 \%$. Out of these 36 girls had menstrual irregularities. Girls with high BMI $>25 \mathrm{~kg} / \mathrm{m}^{2}, 39.62 \%$ irregularities and the rest $60.37 \%$ had no menstrual complaints. Low BMI i.e.; $<18 \mathrm{~kg} / \mathrm{m}^{2}$, only 14 girls out of 33 girls had menstrual irregularities. Study conducted by the Dars et al showed $75.51 \%$ girls had normal BMI and normal menstrual pattern but all the girls with BMI $>25$ $\mathrm{kg} / \mathrm{m}^{2}$ had in frequent cycles. ${ }^{13}$ Similar results were seen in the study conducted by Singh et al. ${ }^{14}$ The association between BMI and menstrual blood loss are very limited. Usually weight loss returns to regular menstrual function by decreasing the aromatisation of androgens to estrogen in adipose tissue.

Menstrual irregularities in adolescent girls are often due to immature hypothalamo-pituitary- gonadal axis but persistent menstrual abnormalities may be associated with polycystic ovarian syndrome. In our study $6 \%$ girls were already diagnosed as PCOS, out of which only $38.89 \%$ were on hormonal treatment and the rest $61.11 \%$ were not taking any medication. Study conducted by Arpana et al showed $1.5 \%$ had been diagnosed as having PCOS ultrasonically but study conducted by Kural et al documented higher prevalence of PCOS i.e.; 22\% taking multiple diagnostic criteria- clinical, biochemical and radiological. ${ }^{15}$

\section{Limitations}

The study did not include any biochemical parameters for comparison and co-relation with menstrual disorders.

\section{CONCLUSION}

There is a high prevalence of menstrual disorders among adolescent girls. These disorders affect the social and academic lives of the adolescents and may be indicators of underlying problems that can become serious in the future. Thus, more attention should be paid to identify and treat these menstrual morbidities. Physical activity plays an 
essential part in reducing menstrual disorders in an adolescent.

Funding: No funding sources

Conflict of interest: None declared

Ethical approval: The study was approved by the Institutional Ethics Committee

\section{REFERENCES}

1. Boswell HB. The adolescent with menorrhagia: why, who, and how to evaluate for a bleeding disorder. $\mathbf{J}$ Pediatr Adolesc Gynecol. 2011;24(4):228-30.

2. Hertweck P, Yoost J. Common problems in pediatric and adolescent gynecology. Expert Review Obstet Gynecol. 2010;5:311.

3. Kulshrestha S, Durrani AM. Prevalence of Menstrual disorders and their association with physical activity in adolescent girls of Aligarh city. Int $\mathrm{J}$ Health Sci Res. 2019;9(8):384-93.

4. Kaul A, Suxena SC, Srivastava P, Rai KR, Agarwal P, Rahat F. Age of Menarche Among Girls at Allahabad, Uttar Pardesh. Indian Inter J Forens Med Toxicol. 2015;13:55.

5. Srivastava P, Varoda A, Venugopal R. Menstrual Cycle Pattern among Adolescent School Girls in Chhattisgarh. The Int. J Indian Psychol. 2016;3:234896.

6. Vanitha D, Edward S, Varadharajan S, Anita RM. A Community Based Study on Menstrual Disorders among the Rural Women of Reproductive Age. Int J Women Health Rep Sci. 2017;5:270-76.

7. Eyclope O, James O. Prevalence of Menstrual Disorders among Adolescent girls in Osogho, South Western Nigeria. Int $\mathbf{J}$ Adolesc Med Heath. 2014;26(1):101-6.

8. Arpana A, Lokeshwari K, Rashmi BM. Menstrual Characteristics and Association of Body Mass Index with Dysmenorrhea among the Medical Students in South India. Indian J Obstet Gynecol. 2019;6(2):1558.

9. Chakrabarti M, Rahaman A, Basu SP. Ultrasonographic Prevalence of Polycystic Ovarian Disease- A Cross Sectional Study in a Rural Mediacl College of West Bengal. IOSR J Dent Med Sci. 2016;15(1):15-20.

10. Karout N, Hawai SM, Altuwaijri S. Prevalence and pattern of menstrual disorders among Lebanese nursing students. East Mediterr Health J. 2012;18(4):346-52.

11. Anandha LS, Saraswathi I, Saravanan A, Ramamchandran C. Prevalence of Premenstrual Syndrome and Dysmenorrhea among Female Medical Students and its Association with College Absenteeism. Int J Biol Med Res. 2011;2;1011-6.

12. Tayebi N, Yazdanpanahi Z, Yektatalab S, Pourahmad S, Akbarzadeh M. The Relationship Between Body Mass Index (BMI) and Menstrual Disorders at Different Ages of Menarche and Sex Hormones. J Natl Med Assoc. 2018;110(5):440-7.

13. Dars S, Sayed K, Yousufzai Z. Relationship of Menstrual Irregularities to BMI and Nutritional Status in Adolescent Girls. Pak J Med Sci. 2014;30(1):1404.

14. Singh M, Rajoura OP, Honnakamble RA. Menstrual patterns and problems in association with body mass index among adolescent school girls. J Family Med Prim Care. 2019;8(9):2855-8.

15. Kural M, Noor NN, Pandit D, Joshi T, Patil A. Menstrual characteristics and prevalence of dysmenorrhea in college going girls. J Family Med Prim Care. 2015;4(3):426-31.

Cite this article as: Vaishali V, Banashree D, Jayati N. Determination of the prevalence and pattern of menstrual disorders in college going adolescent girls in rural Haryana. Int J Reprod Contracept Obstet Gynecol 2021;10:2729-33. 